\title{
Mortality in low- and very low-risk patients undergoing cardiac surgery: Evaluation according to the EuroSCORE II as a new standard
}

\author{
Raul Alfredo Borracci, ${ }^{1,2}$, Miguel Rubio ${ }^{2}$, Julio Baldi Jr. ${ }^{2}$, \\ Rodolfo A. Ahuad Guerrero ${ }^{3}$, Víctor Mauro ${ }^{2}$ \\ ${ }^{1}$ School of Medicine, Austral University, Buenos Aires, Argentina \\ ${ }^{2}$ Hospital de Clínicas “José de San Martín”, School of Medicine, Buenos Aires University, Argentina \\ ${ }^{3}$ School of Medicine, Buenos Aires University, Argentina
}

\begin{abstract}
Background: Only a few reports have analyzed low-risk patient outcomes and in every case, the risk was based on a logistic EuroSCORE $\leq 2$. Since this original EuroSCORE overestimates surgical risk, we developed this study to prospectively evaluate the immediate results of cardiac surgery in patients with an expected mortality risk $\leq 2 \%$ according to the EuroSCORE II as a new gold standard. We also examined the cause of death and whether it could be considered preventable.
\end{abstract}

Methods: A prospective risk stratification of all cardiac surgical patients treated at the Buenos Aires University Hospital of Argentina was performed between 2012 and 2014 using the EuroSCORE II. Causes of death were classified as preventable or not preventable.

Results: From a total of 990 patients, $63.2 \%$ had EuroSCORE II $\leq 2$ (low-risk group) and $32.5 \%$ EuroSCORE II $<1$ (very low-risk group). In the low-risk group, in-hospital mortality was $1.8 \%$, whereas predicted mortality was $1.04 \%$ (AUC 0.765). The observed/expected ratio was 1.73 (95\% CI 0.68-4.43) and the observed-expected difference was 0.76 (95\% CI -0.68-2.10). Fifty-four percent of deaths were considered preventable.

Conclusions: We propose to use and further validate the EuroSCORE II as a new standard for assessing low-risk patients. This model proved to be useful in evaluating the quality standards of local cardiac surgery. The review of cause of death in low-risk patients provided valuable information, which revealed potentially correctable issues. Adoption of a more demanding standard, as the EuroSCORE II to identify low-risk patients, avoids the sense of safety offered by previous versions of the score. (Cardiol J 2015; 22, 5: 495-500)

Key words: risk analysis, perioperative care, surgical complications, EuroSCORE II

Editorial p. 479

\section{Introduction}

Developed countries continue to improve quality standards in cardiac surgery. Today, advances in technology, professional competitiveness and population expectations demand better and increasingly predictable surgical results. The risk stratification models used to assess perioperative mortality, such as the Society of Thoracic Surgeons mortality risk score (STS) [1] and the European System for Cardiac Operative Risk Evaluation II (EuroSCORE II) [2]

Address for correspondence: Dr Raúl A. Borracci, Biostatistics, School of Medicine, Austral University, La Pampa 3030, 1428 Buenos Aires, Argentina, tel: (54-011) 4784-5917, fax: (54-11) 4961-6027, e-mail: raborracci@gmail.com 
propose rigorous quality standards with commonly expected operative risks $<1 \%$.

Behind this process, cardiac surgeons in developing countries try to reproduce these results. However, it is clear that these countries have at least a technological limitation that prevents them from matching their results with international measures. In this sense, technological backwardness and infrastructure constraints are valid arguments to justify not attaining the highest quality standards. These reasons, however, would only be well-founded for patients with severe comorbidities and high expected risk, where perioperative technological support is crucial to make a difference in the results. Instead, it is in very low-risk patients, with an expected lower demand for additional instrumental support, in whom local cardiac surgery should achieve the best quality standards. In this situation, there would be a strong and direct relationship between outcomes and the individual performance of the surgical team during surgery.

To date, only a few reports have analyzed the outcomes in low-risk patients, and in every case risk has been calculated based on a logistic Euro$\mathrm{SCORE} \leq 2$ [3-7]. Since this original EuroSCORE overestimates operative risk [8], we developed this study to prospectively evaluate the immediate results of cardiac surgery in patients with an expected mortality risk $\leq 2 \%$ according to the EuroSCORE II as a new gold-standard. We also examined the cause of death and whether it could be considered preventable.

\section{Methods}

A prospective risk stratification of all cardiac surgical patients treated at the Buenos Aires University Hospital of Argentina, Hospital de Clínicas "José de San Martín" and its associated Clinics, was performed between 2012 and 2014 using the EuroSCORE II. Definitions proposed by the EuroSCORE II were fully adopted and the risk score was determined with an online interactive calculator (http://www.euroscore.org/calc.html). Creatinine clearance was calculated with the Cockroft-Gault formula [9]. All types of surgery were included, except acute aortic dissection, transplant and transcatheter aortic valve implantation. Patient characteristics, surgical details and postoperative outcomes were simultaneously recorded in a computer database. Individuals with a score $\leq 2$ were identified from the database and included in the study. According to our definition, they were categorized as the low-risk group. An extra category was defined when the expected risk of operative mortality was $<1$, and these patients were included in the very low-risk group. Only patients with EuroSCORE II $>2$ were excluded. Primary endpoints were in-hospital and 30-day all cause-mortality. Major complications, overall mortality, cause of death, observed-to-expected operative mortality ratio and observed-expected difference were calculated. Causes of death were classified by 2 senior surgeons and 2 cardiologists into 3 categories: not preventable, preventable (technical error), or preventable (system error). We defined non-preventable death when the cause was an unavoidable and unpredictable event such as pulmonary embolism, stroke, mediastinitis, septicemia or sudden death after discharge. Definitions of technical and system errors were adopted from previous FIASCO studies [3, 4].

Preoperative baseline demographic and clinical comorbid risk variables and operative procedural variables were recorded and analyzed with the approval of the institutional review board.

\section{Statistical analysis}

Observed mortality was calculated according to the number of events reported in each group. Observed/expected $(\mathrm{O} / \mathrm{E})$ mortality ratio and observed-expected $(\mathrm{O}-\mathrm{E})$ mortality difference with their corresponding $95 \%$ confidence intervals $(95 \%$ CI) were calculated for each group. An O/E ratio $>1$ indicated that mortality was higher than predicted with the EuroSCORE II, or that the model underestimated the relative mortality, whereas a ratio $<1$ showed that mortality was lower than expected, or that the model overestimated mortality. If the $95 \% \mathrm{CI}$ for the $\mathrm{O} / \mathrm{E}$ ratio excluded the value 1 , this was considered statistically significant. Similarly, a value of $\mathrm{O}-\mathrm{E}>0$ meant that mortality was higher than that predicted with the EuroSCORE II, or that the model underestimated absolute mortality, whereas a value $<0$ indicated that mortality was lower, or that the model overestimated mortality. If the $95 \% \mathrm{CI}$ for the O-E difference excluded the value 0 , this was considered statistically significant. For the statistical analysis, continuous variables were expressed as mean \pm standard deviation (SD). The Kolmogorov-Smirnov goodness-of-fit test was used to analyze normal distributions, and comparison between continuous variables was done with Student's t-test. Univariate comparison of dichotomous variables was performed using the $\chi^{2}$ test. Yates' corrected $\chi^{2}$ was used when cell expected values were between 3 and 5 , while 2 -tailed Fisher's exact test was used when values 
Table 1. Preoperative population characteristics and immediate postoperative outcomes.

\begin{tabular}{|c|c|c|c|}
\hline Variables & Low-risk $(n=626)$ & Very low-risk (n = 322) & $\mathbf{P}$ \\
\hline \multicolumn{4}{|l|}{ Pre-and intraoperative } \\
\hline Age [years] (range) & $63.2 \pm 10.0(26-86)$ & $58.8 \pm 8.7(35-80)$ & $<0.0001$ \\
\hline Male gender & $502(80.2 \%)$ & $293(91.0 \%)$ & $<0.0001$ \\
\hline Insulin dependent diabetes & $7(1.1 \%)$ & $3(0.9 \%)$ & 0.945 \\
\hline Stroke & $10(1.6 \%)$ & $5(1.6 \%)$ & 0.824 \\
\hline Chronic lung disease & $11(1.8 \%)$ & $3(0.9 \%)$ & 0.475 \\
\hline Pulmonary hypertension & $21(3.4 \%)$ & $5(1.6 \%)$ & 0.162 \\
\hline Extracardiac arteriopathy & $7(1.1 \%)$ & $3(0.9 \%)$ & 0.945 \\
\hline Unstable angina* & $17(2.7 \%)$ & $11(4.9 \%)$ & 0.547 \\
\hline Active endocarditis & $3(0.5 \%)$ & $0(0.0 \%)$ & 0.555 \\
\hline Renal failure (dialysis) & $2(0.3 \%)$ & $0(0.0 \%)$ & 0.551 \\
\hline Prior cardiac surgery (redo) & $2(0.3 \%)$ & $0(0.0 \%)$ & 0.789 \\
\hline Moderate-severe LV dysfunction & $54(8.6 \%)$ & $19(5.9 \%)$ & 0.136 \\
\hline \multicolumn{4}{|l|}{ Type of surgery: } \\
\hline Coronary & $406(64.9 \%)$ & $223(69.3 \%)$ & 0.175 \\
\hline Valvular & $171(27.3 \%)$ & $88(27.3 \%)$ & 0.997 \\
\hline Miscellaneous** & $49(7.8 \%)$ & $11(3.4 \%)$ & 0.008 \\
\hline Off-pump coronary bypass $* * *$ & $83(20.4 \%)$ & $44(13.6 \%)$ & 0.862 \\
\hline At least one IMA graft*** & $393(96.8 \%)$ & $216(96.9 \%)$ & 0.191 \\
\hline $\begin{array}{l}\text { Cardiopulmonary } \\
\text { bypass time [min] }\end{array}$ & $61.4 \pm 11.5$ & $59.4 \pm 8.8$ & 0.006 \\
\hline Cross-clamp time [min] & $35.6 \pm 10.6$ & $34.1 \pm 9.1$ & 0.031 \\
\hline \multicolumn{4}{|l|}{ Postoperative } \\
\hline In-hospital mortality & $11(1.8 \%)$ & $3(0.93 \%)$ & 0.404 \\
\hline 30-day mortality & $13(2.1 \%)$ & $4(1.2 \%)$ & 0.510 \\
\hline Operating theatre extubation & $465(74.3 \%)$ & $251(78.2 \%)$ & 0.213 \\
\hline \multicolumn{4}{|l|}{ Major complications: } \\
\hline Reoperation for bleeding & $12(1.9 \%)$ & $6(1.9 \%)$ & 0.954 \\
\hline Infarction (Q type) $)^{* * *}$ & $6(1.5 \%)$ & $3(1.3 \%)$ & 0.754 \\
\hline Low cardiac output & $4(0.6 \%)$ & $2(0.6 \%)$ & 1.000 \\
\hline Prolonged ventilation & $3(0.5 \%)$ & $1(0.3 \%)$ & 1.000 \\
\hline Stroke & $4(0.6 \%)$ & $0(0.0 \%)$ & 0.306 \\
\hline De novo dialysis & $2(0.3 \%)$ & $0(0.0 \%)$ & 0.551 \\
\hline Mediastinitis & $5(0.8 \%)$ & $3(0.9 \%)$ & 0.871 \\
\hline
\end{tabular}

*Defined as nitrate infusion at operating theatre arrival; **Miscellaneous surgery included: cardiac neoplasm, combined surgery, ascending aortic aneurysm and atrial septal defect; ${ }^{* *}$ Calculated exclusively for coronary surgery; LV — left ventricle; IMA — internal mammary artery

were below 3. Finally, the area under the receiver operating characteristic (ROC) curve (AUC) was determined to assess EuroSCORE II performance. Data analysis was performed with SPSS Statistics for Windows, Version 17.0 (Chicago: SPSS Inc.) and Epi Info ${ }^{\mathrm{TM}}$ 7.1.3.0, and a $\mathrm{p}$ value $\leq 0.05$ was considered statistically significant.

\section{Results}

Between 2012 and 2014, 990 adult patients underwent cardiac surgery at our institution, 626
(63.2\%) of whom were identified as having EuroSCORE II $\leq 2$ (low-risk group) and $322(32.5 \%)$ EuroSCORE II $<1$ (very low-risk group). Population characteristics and the immediate postoperative adverse events in both groups are shown in Table 1. Among preoperative characteristics, there was no case of active endocarditis, dialysis or prior cardiac surgery (redo) in very low-risk patients. When comparing risk groups, low-risk patients were older, with higher prevalence of women, longer cardiopulmonary bypass and cross-clamping times, and less isolated coronary surgery than in very low-risk patients. 


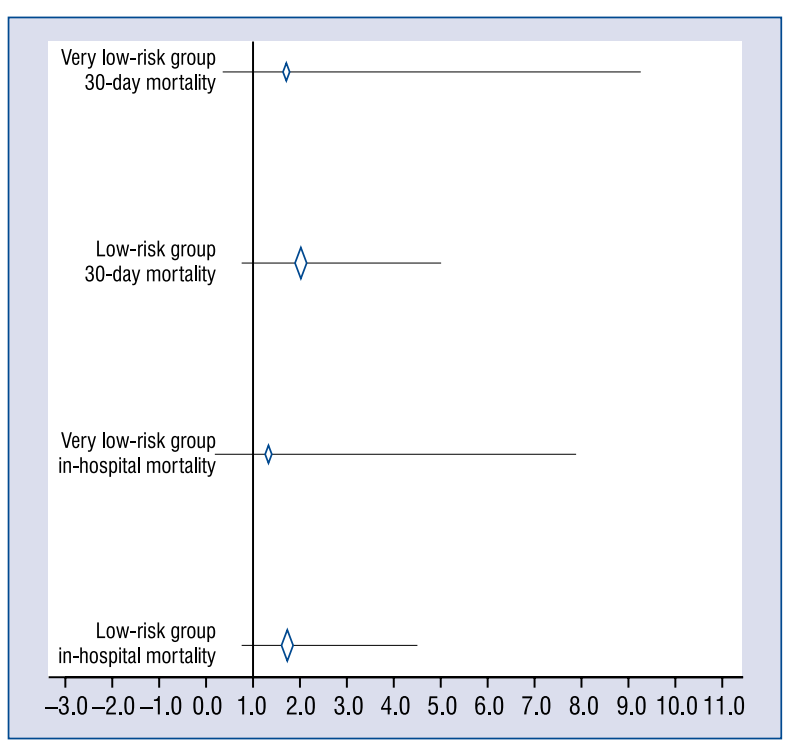

Figure 1. Observed/expected mortality ratio with the corresponding $95 \%$ confidence interval for in-hospital and 30-day overall mortality in low- and very low-risk groups.

In the low-risk group, in-hospital overall mortality was $1.8 \%$ (11 observed deaths), whereas the one predicted by the EuroSCORE II was $1.04 \pm$ $\pm 0.41 \%$ (mean value of 7 expected deaths) (AUC 0.765 [95\% CI 0.621-0.908]). In the very low-risk group, in-hospital overall mortality rate was $0.93 \%$ (3 observed deaths), while the mortality rate predicted by EuroSCORE II was $0.70 \pm 0.14 \%$ (mean value of 2 expected deaths). Thirty-day overall mortality in the low-risk group was $2.1 \%$ (13 observed deaths), and 1.2\% (4 observed deaths) in the very-low-risk group. Regarding in-hospital mortality, the $\mathrm{O} / \mathrm{E}$ ratio in the low-risk group was 1.73 (95\% CI 0.68-4.43); while the $\mathrm{O} / \mathrm{E}$ ratio in the very low-risk group was 1.33 (95\% CI 0.22-7.89). When assessing 30-day overall mortality, the $\mathrm{O} / \mathrm{E}$ ratio in the low-risk group was 2.02 (95\% CI 0.81-5.03); while the $\mathrm{O} / \mathrm{E}$ ratio in the very low-risk group was 1.71 (95\% CI 0.32-9.27) (Fig. 1). The O-E difference for in-hospital mortality in the low-risk group was 0.76 (95\% CI -0.68-2.10); while in the very low-risk group it was $0.23(95 \%$ CI -1.21-1.67). For 30-day mortality, the O-E difference in the low-risk group was 1.06 (95\% CI -0.33-2.40); whereas in the very low-risk group it was 0.50 (95\% CI -1.00-2.10) (Fig. 2).

The causes of death in low-risk patients undergoing cardiac surgery are summarized in Table 2. The table also identifies the problems used to classify death as preventable or not. Seven deaths

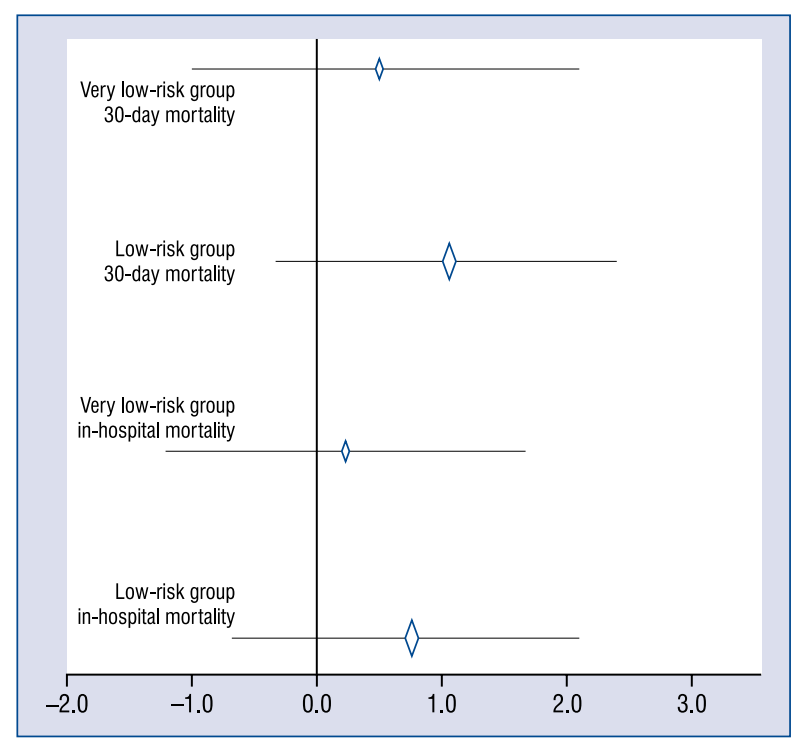

Figure 2. Observed-expected mortality difference with the corresponding $95 \%$ confidence interval for in-hospital and 30-day overall mortality in low- and very low-risk groups.

out of $13(54 \%)$ were considered preventable and related to renal failure due to excessive blood transfusion, unresolved sternal wound complication, problems with anticoagulation and antiarrhythmic treatments, delayed pacemaker implantation, technical problem with bypass grafting and systemic embolism during surgery.

\section{Discussion}

Perioperative death in low-risk patients is uncommon and had not been thoroughly studied until recently [3-7]. Previous studies defined low-risk with a logistic EuroSCORE $\leq 2$ or an additive EuroSCORE $\leq 3$, and investigated whether death could be considered preventable due to a technical or system error. Recently, the EuroSCORE II has been introduced in order to adjust risk overestimation attributed to the original version of the score. The EuroSCORE II is an update of the original logistic EuroSCORE model and is derived from a more contemporary dataset which reflects current cardiac surgical outcomes better [2]. Based on this new score we defined a low-risk population when expected mortality risk was $\leq 2 \%$, and a very lowrisk population when risk was $<1 \%$.

In this series, in-hospital mortality in patients with EuroSCORE II $\leq 2$ was $1.8 \%$, and $0.93 \%$ when the EuroSCORE II was $<1$. Though surgical performance was adequate according to this new 
Table 2. Surgical procedure, cause of death, and problems identified in low-risk cardiac surgery patients, according to EuroSCORE II.

\begin{tabular}{|c|c|c|c|c|c|c|c|}
\hline No. & Gender & Age & Operation & Time & Cause of death & Preventable & Identified problem \\
\hline 1 & Female & 75 & CABG & In-hospital & Renal failure & Yes - system & $\begin{array}{l}\text { Hemorrhage, excessive } \\
\text { blood transfusion }\end{array}$ \\
\hline 2 & Male & 81 & $\mathrm{CABG}+\mathrm{AVR}$ & In-hospital & $\begin{array}{l}\text { Multiple organ } \\
\text { failure }\end{array}$ & No & Septicemia \\
\hline 3 & Male & 61 & CABG & In-hospital & Perioperative MI & Yes - technical & $\begin{array}{c}\text { Problem with right } \\
\text { coronary graft }\end{array}$ \\
\hline 4 & Male & 55 & CABG & In-hospital & Perioperative MI & No & $\begin{array}{l}\text { Hemorrhagic pericarditis } \\
\text { discovered during surgery }\end{array}$ \\
\hline 5 & Female & 52 & MYXOMA & In-hospital & Stroke & Yes - technical & $\begin{array}{c}\text { Embolism due to } \\
\text { atrial septal defect } \\
\text { (right atrium myxoma) }\end{array}$ \\
\hline 6 & Male & 62 & CABG & In-hospital & $\begin{array}{l}\text { Ventricular } \\
\text { arrhythmia }\end{array}$ & Yes - technical & $\begin{array}{l}\text { Possible inappropriate } \\
\text { antiarrhythmic treatment }\end{array}$ \\
\hline 7 & Male & 72 & CABG & In-hospital & $\begin{array}{l}\text { Multiple organ } \\
\text { failure }\end{array}$ & No & Mediastinitis \\
\hline 8 & Male & 74 & CABG & In-hospital & Cardiogenic shock & No & Unknown origin \\
\hline 9 & Female & 75 & AVR & In-hospital & $\begin{array}{l}\text { Complete } \\
\text { A-V block }\end{array}$ & Yes - technical & $\begin{array}{l}\text { Delayed pacemaker } \\
\text { implantation }\end{array}$ \\
\hline 10 & Male & 66 & CABG & In-hospital & $\begin{array}{l}\text { Cardiac vasoplegia } \\
\text { syndrome }\end{array}$ & No & Unknown origin \\
\hline 11 & Male & 75 & CABG & In-hospital & $\begin{array}{l}\text { Reoperation } \\
\text { for bleeding }\end{array}$ & No & Hemorrhage \\
\hline 12 & Male & 69 & CABG & 30-day & $\begin{array}{l}\text { Respiratory } \\
\text { insufficiency }\end{array}$ & Yes - system & $\begin{array}{l}\text { Sternal wound } \\
\text { dehiscence }\end{array}$ \\
\hline 13 & Female & 75 & AVR & 30-day & $\begin{array}{l}\text { Sudden death } \\
\text { after discharge }\end{array}$ & Yes - system & $\begin{array}{c}\text { Potential problem } \\
\text { with anticoagulation }\end{array}$ \\
\hline
\end{tabular}

CABG — coronary artery bypass grafting; A-V — atrioventricular; AVR — aortic valve replacement; $\mathrm{MI}$ - myocardial infarction

risk model standard, we found that there is still some room for improvement, since over half of deaths were potentially preventable. In previous studies, some unforeseen events such as stroke or mediastinitis were usually presumed to be nonpreventable [6]. However, a stroke could arise from aortic debris embolism during cross-clamping or from air embolism in open heart surgery, and in these situations, the event might be considered preventable. Therefore, we assumed that classification of the causes of deaths as preventable or not might be affected by a high degree of subjectivity, and depend on identifying the actual circumstances and mechanisms leading to death.

The operative mortality rates for cardiac surgery continue to fall despite older and sicker patients, indicating better quality of in-hospital care [4]. Hence, new standards must be chosen to stratify surgical risk. EuroSCORE II is a challenging new standard, and nearly one-third of all our cardiac surgical patients were assigned as having a very low expected risk of mortality. Certainly, with this risk model, many patients with a previous logistic EuroSCORE $>2$ could be reassigned to the low- or very low-risk groups, according to the EuroSCORE II.

A recent meta-analysis by Guida et al. [10], involving 145,592 patients, confirmed the global validity of EuroSCORE II as a tool to stratify patient risk. However, a single large study assessing the performance of this score in United Kingdom cardiac surgery (23,740 procedures from the Society of Cardiothoracic Surgery Database), showed poor calibration for isolated coronary artery bypass grafting surgery in both the lowest and highest risk patients [11].

Since the incidence of mortality is low, the investigation of the cause of death in very low-risk patients requires a larger group of individuals to demonstrate accurate mortality rates. In this sense, the major limitation of this work was the relatively small number of patients and deaths in the sample. Nevertheless, we determined that it is possible to achieve a good performance on low- and 
Table 3. Studies analyzing death of low-risk patients undergoing cardiac surgery.

\begin{tabular}{lccccc}
\hline Year of publication & $\begin{array}{c}\text { Period of } \\
\text { study }\end{array}$ & $\begin{array}{c}\text { Number of } \\
\text { patients }\end{array}$ & $\begin{array}{c}\text { Type of } \\
\text { surgery }\end{array}$ & $\begin{array}{c}\text { EuroSCORE } \\
\text { and cut-off }\end{array}$ & $\begin{array}{c}\text { In-hospital } \\
\text { mortality }\end{array}$ \\
\hline Freed (2009) [3] & $1996-2005$ & 4294 & All type & Logistic $\leq 2$ & $0.37 \%$ \\
Janiec (2010) [5] & $2001-2009$ & 3924 & All type & Additive $\leq 3$ & $0.38 \%$ \\
Farid (2013) [4] & $2006-2012$ & 2549 & All type & Logistic $\leq 2$ & $0.27 \%$ \\
Cakalagaoglu (2014) [6] & $2002-2007$ & 2570 & CABG & Logistic $\leq 2$ & $0.93 \%$ \\
Ercan (2014) [7] & $2002-2007$ & 478 & CABG & Logistic $\leq 2$ & $1.04 \%$ \\
Current series & $2012-2014$ & 626 & All type & EuroSCORE II $\leq 2$ & $1.76 \%$ \\
Current series & $2012-2014$ & 322 & All type & EuroSCORE II < 1 & $0.93 \%$ \\
\hline
\end{tabular}

CABG - coronary artery bypass grafting

very low-risk patients undergoing cardiac surgery, in a context of technological constraints. Although the observed in-hospital mortality in very low-risk patients was $0.93 \%$, the expected risk based on the EuroSCORE II was even lower (0.70), and this difference could reach statistical significance in a larger sample.

Table 3 summarizes the findings of different studies analyzing death in low-risk patients and virtually 3 of them (from United Kingdom [3, 4] and Sweden [5]) showed mortality rates well below $1 \%$. The remaining 2 studies from Turkey reported similar results to ours, though they only included coronary artery bypass grafting that has a well-known lower risk of operative mortality than other types of open heart surgery [6, 7].

\section{Conclusions}

In conclusion, we propose to use and further validate the EuroSCORE II as a new standard for assessing low- and very low-risks patient outcomes. Even in the context of the technological constraints occurring in a developing country, this risk model proved to be useful in evaluating the quality standards of local cardiac surgery. Additionally, the review of cause of death in low-risk patients provides valuable information which may reveal potentially correctable issues, and eventually lead to improvements in the quality of care. Furthermore, the adoption of a more demanding standard, as the EuroSCORE II to identify lowrisk patients, avoids the sense of safety offered by previous versions of the score.

Conflict of interest: None declared

\section{References}

1. Shahian DM, O'Brien SM, Filardo G et al. The Society of Thoracic Surgeons 2008 cardiac surgery risk models: Part 1-coronary artery bypass grafting surgery. Ann Thorac Surg, 2009; 88: S2-S22.

2. Nasef SA, Roques F, Sharples LD et al. EuroSCORE II. Eur J Cardiothorac Surg, 2012; 41: 734-744.

3. Freed DH, Drain AJ, Kitcat J, Jones MT, Nashef SAM. Death in low-risk cardiac surgery: The failure to achieve a satisfactory cardiac outcome (FIASCO) study. Interact Cardiovasc Thorac Surg, 2009; 9: 623-625.

4. Farid S, Page A, Jenkins D, Jones MT, Freed D, Nashef SAM. FIASCO II failure to achieve a satisfactory cardiac outcome study: The elimination of system errors. Interact Cardiovasc Thorac Surg, 2013; 17: 116-119.

5. Janiec M, Sartipy U. Death in low-risk cardiac surgery: Stockholm experience. Interact Cardiovasc Thorac Surg, 2010; 11: 547-549.

6. Cakalagaoglu C, Koksal C, Adademir T et al. Analysis of mortality in low-risk patients undergoing coronary artery bypass grafting. Cardiovasc J Afr, 2013; 24: 247-250.

7. Ercan A, Karal IH, Gurbuz O, Kumtepe G, Onder T, Saba D. A comparison of off-pump and on-pump coronary bypass surgery in patients with low EuroSCORE. J Cardiothorac Surg, 2014; 9: 105.

8. Borracci RA, Rubio M, Celano L, Ingino CA, Allende NG, Ahuad Guerrero RA. Prospective validation of EuroSCORE II in patients undergoing cardiac surgery in Argentinean centres. Interact Cardiovasc Thorac Surg, 2014; 18: 539-543.

9. Cockcroft D, Gault MK. Prediction of creatinine clearance from serum creatinine. Nephron, 1976; 16: 31-41.

10. Guida P, Mastro F, Scrascia G, Whitlock R, Paparella D. Performance of the European System for Cardiac Operative Risk Evaluation II: A meta-analysis of 22 studies involving 145,592 cardiac surgery procedures. J Thorac Cardiovasc Surg, 2014; 148: 3049-3057.

11. Grant SW, Hickey GL, Dimarakis I et al. How does EuroSCORE II perform in UK cardiac surgery: An analysis of 23740 patients from the Society for Cardiothoracic Surgery in Great Britain and Ireland National Database. Heart, 2012; 98: 1568-1572. 